\title{
Butt Joining of Magnesium Alloy Sheet by Shot Peening
}

\author{
Yasunori Harada, Makoto Fukunaga* and Atsushi Yamamoto \\ Graduate School of Engineering, University of Hyogo, Himeji 671-2280, Japan
}

Magnesium and its alloys are very attractive for light weight applications. However, their use is complicated by the fact that dissimilar metals are joined by fusion welding. In the present study, the ability of shot peening to enhance butt joining of a magnesium alloy sheet with dissimilar material sheets was investigated. Shot peening improves the performance of the engineering components. In this process the substrate undergoes a large plastic deformation near its surface when hit by many shots. The substrate material close to the surface flows during shot peening. This plastic flow is characterized by a shear droop at the edge of the substrate, namely, the peened material overflows at the edge. When the dissimilar metal sheets with notched edges are connected without a level difference and then the connection is shot-peened, the sheets can be joined by the plastic flow generated by the large plastic deformation during shot peening. In this experiment, an air shot peening machine was used. The influences of air pressure and peening time on the joinability were examined. The joint strength increased with peening time, i.e., the amount of plastic flow. It was found that the present method can be used to enhance the butt joining of a magnesium alloy sheet with a dissimilar material sheet. [doi:10.2320/matertrans.MC200735]

(Received October 5, 2007; Accepted January 15, 2008; Published March 5, 2008)

Keywords: shot peening, surface treatment, butt joining, magnesium alloy, joinability, plastic flow, plastic deformation, joint strength

\section{Introduction}

Magnesium and its alloys are used widely in industry because of their excellent properties such as light weight and high specific tensile strength. In order to improve the productivity and the functionality of the magnesium materials, joining methods have been actively investigated. Common liquid-state joining processes are arc and resistance welding. Solid-phase joining processes using plastic deformation, such as cold and friction welding, are also widely used. These processes are an important and necessary aspect of manufacturing operations.

Several kinds of welding techniques can be used with magnesium materials. The effects of welding conditions on the microstructures and mechanical properties of magnesium alloy AZ91D using a tungsten inert gas welding process (TIG) have been investigated, ${ }^{1)}$ and the microstructure characteristics of TIG welded to $\mathrm{Mg} / \mathrm{Al}$ were reported. ${ }^{2)}$ The weldability of magnesium alloy AZ31 sheet welded by a metal inert gas welding process (MIG) was also carried out. ${ }^{3)}$ Further, laser welding and electron beam welding processes for magnesium materials are an important joining method in the manufacture of automotive and aerospace parts. The effects of welding speed and defocusing distance on weldability of AZ31B sheets using the laser-arc hybrid process $^{4)}$ and the mechanical properties of AZ91D plate welded by the electron beam welding process ${ }^{5)}$ were reported.

On the other hand, the friction stir welding process (FSW) is used for solid-state joining of a variety of magnesium alloys rods. In this process, a rotating tool is inserted into the materials to be joined. This technique offers advantages for grain refinement, since the material is subjected to a local plastic deformation at high temperatures induced by the rotating tool. The microstructure and bond strength of AZ31 alloy welded by $\mathrm{FSW}^{6)}$ and the effect of welding speed on the material flow pattern in FSW of $\mathrm{AZ31}{ }^{7)}$ were studied.

*Graduate Student, University of Hyogo
However, it is difficult to join magnesium materials to dissimilar metals by the welding process, especially butt joining of thin sheets.

Although shot peening process is widely used to improve the performance of engineering components, its ability to improve surface properties has recently been studied. The dry coating techniques ${ }^{8)}$ and cold splay ${ }^{9)}$ are used for coating. The metal particles and the substrate can be joined by the adhesion or embedding of particles at high speed. The authors have proposed a lining method by shot peening; ${ }^{10,11)}$ peening with many shots caused the foil to be successfully joined over the surface of the substrate. The pressure generated by many shots hitting is used for the lining of dissimilar foils. We also applied shot peening to the lining of the hard powders such as cemented carbide and ceramics to improve the wear resistance of aluminum and magnesium alloys. ${ }^{12)}$ The hard powders were successfully bonded over the surface. In addition, we have applied these processes to the joining of dissimilar materials. ${ }^{13,14)}$

In shot peening, the peening effects are characterized by the fact that the surface layer undergoes large plastic deformations due to the collision with the shot. When the machined part with the bore and the groove is excessively shot-peened, the accuracy of the shape is lowered as the amount of plastic flow increases. Consequently, plastic flow characterized by shear droop occurs at the edge of the substrate due to shot peening.

The plastic flow makes the joining of the implant possible. When the dissimilar material is set in a hollow space on the surface of the substrate and then shot peened, it can be joined to the substrate by the overflow material generated by the large plastic deformations that occur during shot peening. This approach has been applied to the butt joining of thin sheets.

In the present study, the butt joining of a magnesium alloy sheet with a dissimilar material sheet using a shot peening process was carried out. The influences of peening time and shot material on joinability were mainly examined. Joinability was evaluated by tensile test. 


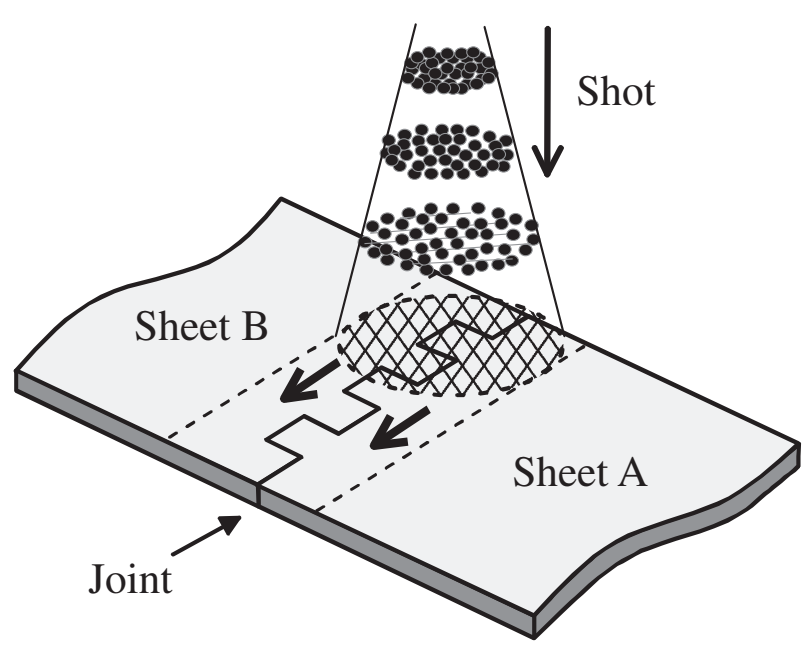

Fig. 1 Schematic illustration of the method of butt joining of dissimilar metal sheets by shot peening.

\section{Experimental Procedure}

\subsection{Method of butt joining}

The method of the butt joining of dissimilar material sheets by shot peening shown in Fig. 1 was used. In the butted area, the edges of the two sheets are notched. When the connection of the convex part is shot-peened, the surface layer is deformed by the collision with the shot. The large plastic deformation that occurs on the surface layer generates overflow material in the edge of the sheet that fills the joint cavity between the two sheets. Thus, the sheets are joined without a level difference. This method is similar to joining by caulking. In this method, both faces of the connection are shot-peened primarily.

\subsection{Processing equipment and used materials}

The shot peening treatment was performed using an airtype peening machine (Sintobrator Ltd., MY-30B) with an air-orifice with a diameter of $3 \mathrm{~mm}$ and an injection-nozzle with a diameter of $6 \mathrm{~mm}$. Air pressure and peening time were controlled in the experiment. The shots used were made of high carbon cast steel and cemented carbide with an average diameter of $0.1 \mathrm{~mm}$. Air pressure was $0.4 \mathrm{MPa}$ and the peening time was in the range of 30-240 s. The conditions used for the shot peening experiment are summarized in Table 1.

The sheets were commercial magnesium alloy AZ31B, low-carbon steel SPCC, stainless steel SUS304, and pure aluminum A1050. A rectangular sheet was used that was $30 \mathrm{~mm}$ wide, $60 \mathrm{~mm}$ long, and $0.8 \mathrm{~mm}$ thick. The edge was cut into the desired shape of $3 \mathrm{~mm}$ wide by $3 \mathrm{~mm}$ long. The materials used for the experiment are also summarized in Table 1.

\subsection{Evaluation of joint strength}

The joint strength between the joined sheets was evaluated by tensile test using a test machine INSTRON-5582 at a cross head speed of $2 \mathrm{~mm} / \mathrm{min}$. The joint strength was defined as the ratio of the maximal load at joint failure to the total contact area; except for the area perpendicular to the direction of the tensile axis.
Table 1 Working conditions used for shot peening experiment.

\begin{tabular}{ll}
\hline Equipment & Air peening type \\
\hline Shot material & $\begin{array}{l}\text { High carbon cast steel }(700 \mathrm{HV}), \\
\text { Cemented carbide }(1400 \mathrm{HV})\end{array}$ \\
\hline Shot diameter & $0.10 \mathrm{~mm}$ \\
\hline Air pressure & $0.4 \mathrm{MPa}$ \\
\hline Peening time & $30-240 \mathrm{~s}$ \\
\hline Working temperature & Room temperature \\
\hline Sheet & Magnesium alloy AZ31B, Low-carbon steel \\
$(t=0.8 \mathrm{~mm})$ & SPCC, Stainless steel SUS304, Pure \\
\hline Atmosphere & aluminum A1050, Polycarbonate PC \\
\hline
\end{tabular}
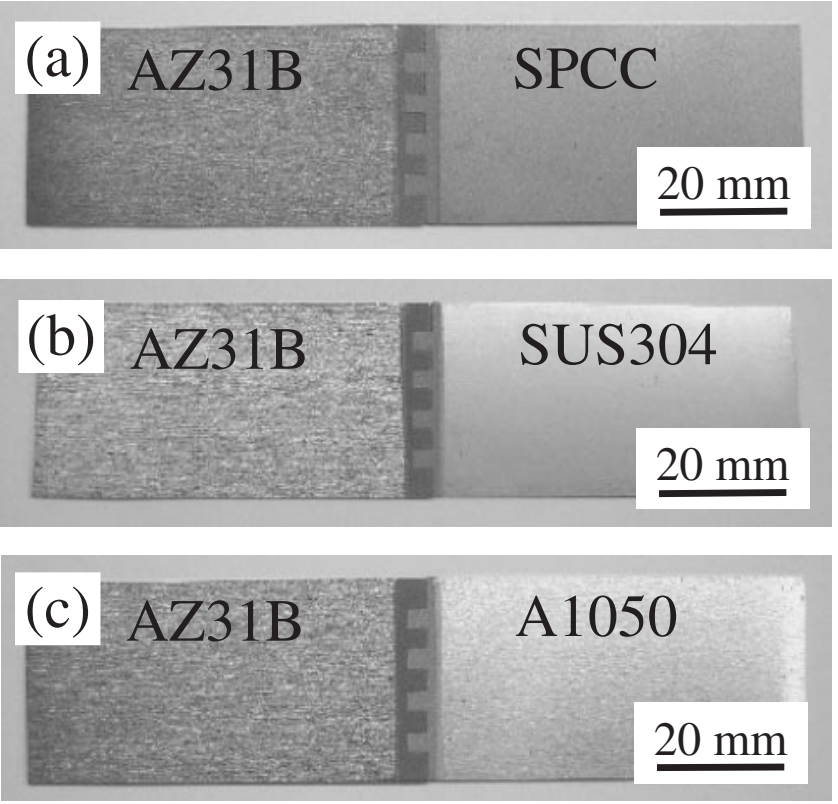

Fig. 2 Appearances of butt joined AZ31B/metal workpieces after shot peening. (a) AZ31B/SPCC, (b) AZ31B/SUS304, (c) AZ31B/A1050.

\section{Results and Discussion}

\subsection{Appearance of butt joined sheets}

The appearances of the butt joined sheets by shot peening are shown in Fig. 2. The peening time is $60 \mathrm{~s}$. The dissimilar metal sheets are low-carbon steel SPCC (a), stainless steel SUS304 (b), and pure aluminum (c). In all workpieces, the clearance at a contact zone disappears due to particle bombardment, because shot peening causes large plastic deformation of surfaces. The magnesium alloy AZ31B and the dissimilar metal sheets were successfully joined without a level difference.

The surface conditions of the sheet were observed by SEM after shot peening. The unpeened and peened surfaces for the AZ31B/SPCC workpiece are given in Fig. 3. After shot peening for $30 \mathrm{~s}$, the clearance at the joint disappeared due to the collision with the shot. The convex parts underwent large plastic deformations near the surface due to the collision with the shot. 

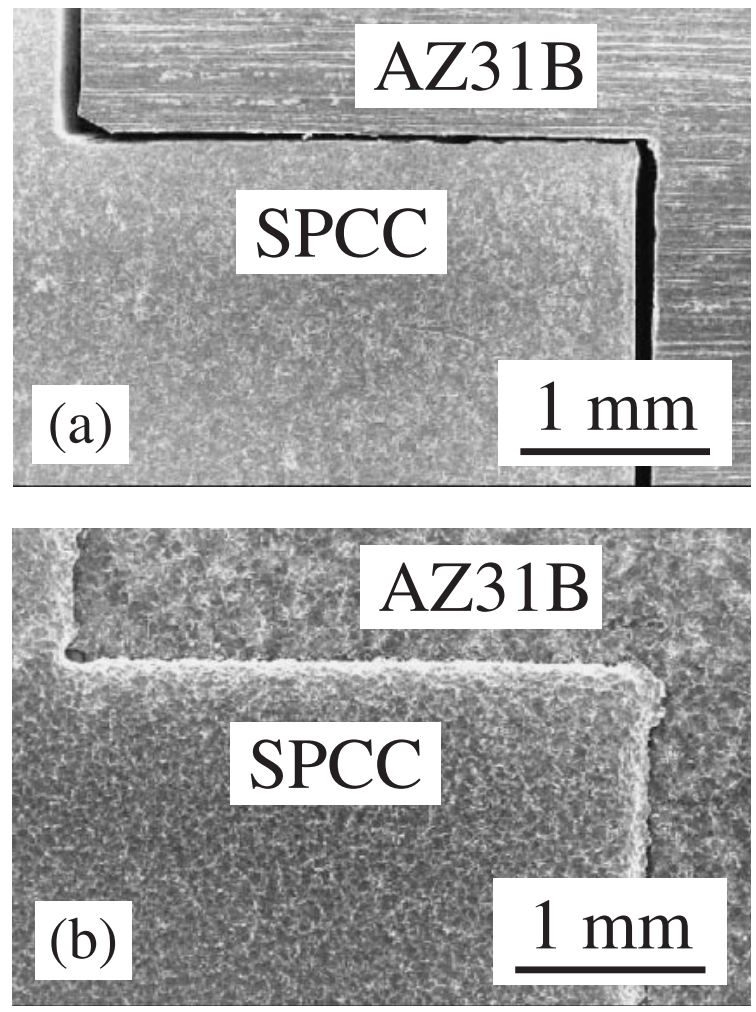

Fig. 3 SEM photomicrographs of the surfaces of AZ31B/SPCC workpieces. (a) Unpeened, (b) Peened at $0.4 \mathrm{MPa}$ for $30 \mathrm{~s}$.

SEM photomicrographs of the cross-sections observed on the joined AZ31B/SPCC workpieces after the tensile test are shown in Fig. 4. The upper and lower sides of the workpiece were shot-peened. After the tensile test, no seizure occurred in the fractured surfaces. The scratches generated by the tensile test were observed on sides close to the peened surfaces, since the material near the surface was deformed by the impact of the shot. However, there are no scratches at the midpoint of the cross-section. The scratches increase with the degree of plastic deformation near the surface. It was found that only the joining was formed where the two sheets meet.

\subsection{Joinability}

The magnesium sheet was successfully joined to the dissimilar metal sheets by shot peening even though the contact area of the two sheets was small. The joint strength of the joined workpieces was evaluated by a tensile test. The joint strength of the AZ31B/ferrous workpiece was measured, and the effect of the shot material on joint strength was also examined. Figure 5 shows variation of the joint strength with peening time for the joined workpieces. The ferrous sheets are low-carbon steel SPCC (a) and stainless steel SUS304 (b). In all workpieces, the joint strength increases with peening time. The strength rises particularly rapidly with peening times beyond $120 \mathrm{~s}$ due to the existence of space between the dissimilar metal sheets. Namely, the strength is not raised until the clearance near the surface is sufficiently filled with the deformed material. The joint strength of the workpiece peened by the cemented carbide media is higher than that by the cast steel media. Compared with the steel media, the cemented carbide media has higher kinetic energy
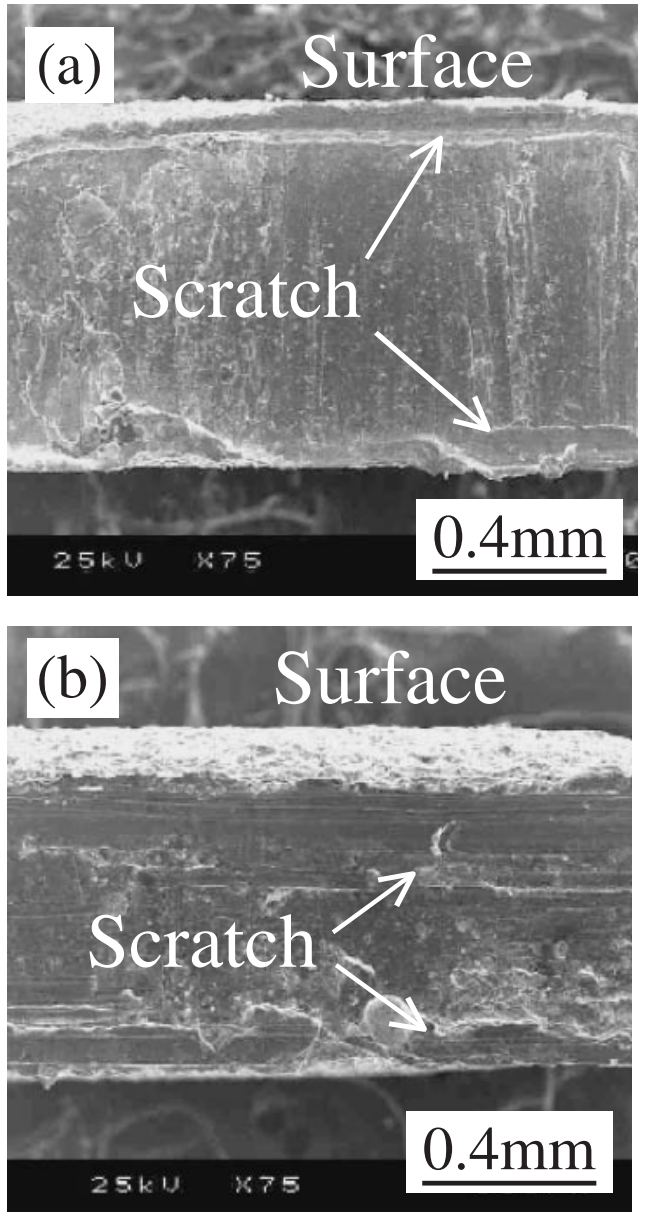

Fig. 4 SEM photomicrographs of the cross-sections observed on the joined AZ31B/SPCC workpieces after tensile test. (a) sheet SPCC peened for $30 \mathrm{~s}$ by cast steel media, (b) sheet AZ31B peened for $180 \mathrm{~s}$ by cemented carbide media.

at collision and this causes greater plastic deformation of the surfaces. These findings imply that one way to increase the joint strength is to enlarge the contact area.

The joint strength of the AZ31B/nonferrous workpiece was measured. The relation between joint strength and peening time for the joined workpieces is shown in Fig. 6. The nonferrous sheet is pure aluminum A1050. Although the surface layer exhibited sufficient plastic deformation at peening times near $30 \mathrm{~s}$, the joint strength generated by the plastic deformations is somewhat low. Even when the surface is shot-peened by the cemented carbide media, the joint strength of the AZ31B/nonfeerous workpiece is lower than that of the AZ31B/ferrous workpiece (see Fig. 4). This is because the flow stress of pure aluminum is low.

\subsection{Improvement of joinability}

To enhance joinability, trapezoidal (a) and jagged (b) edge shapes in the contact zone were tested (Fig. 7). In the former case, the angle $\theta$ was about 5 degrees. In the later case, the cutting depth $\mathrm{x}$ was about $0.5 \mathrm{~mm}$. The two sheets are anchored at both edges in the contact area and are very stable.

The maximum tensile load and peening time for the AZ31B/SPCC workpieces with the modified shapes of contact edge after shot peening are summarized in Fig. 8. The peening time was from $60 \mathrm{~s}$ to $120 \mathrm{~s}$. The tensile results 

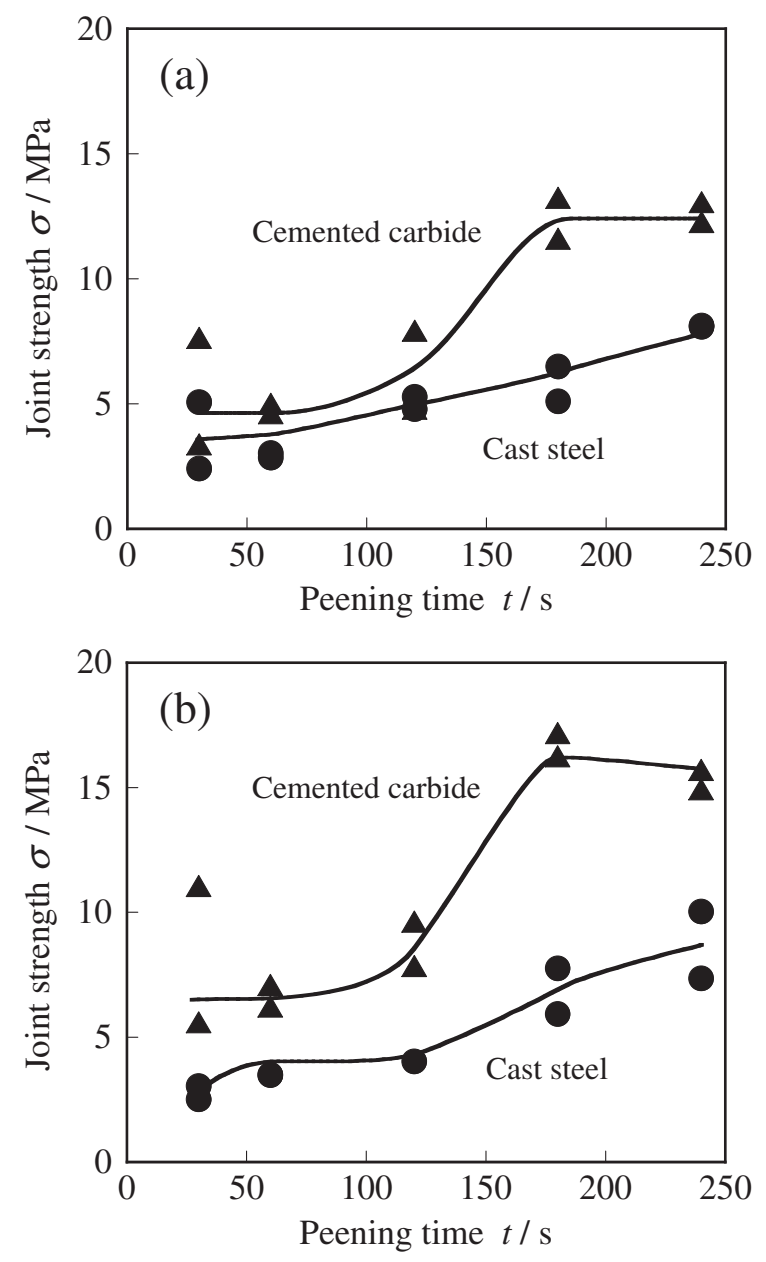

Fig. 5 Variations of joint strength with peening time for AZ31B/ferrous workpieces. (a) AZ31B/SPCC, (b) AZ31B/SUS304.

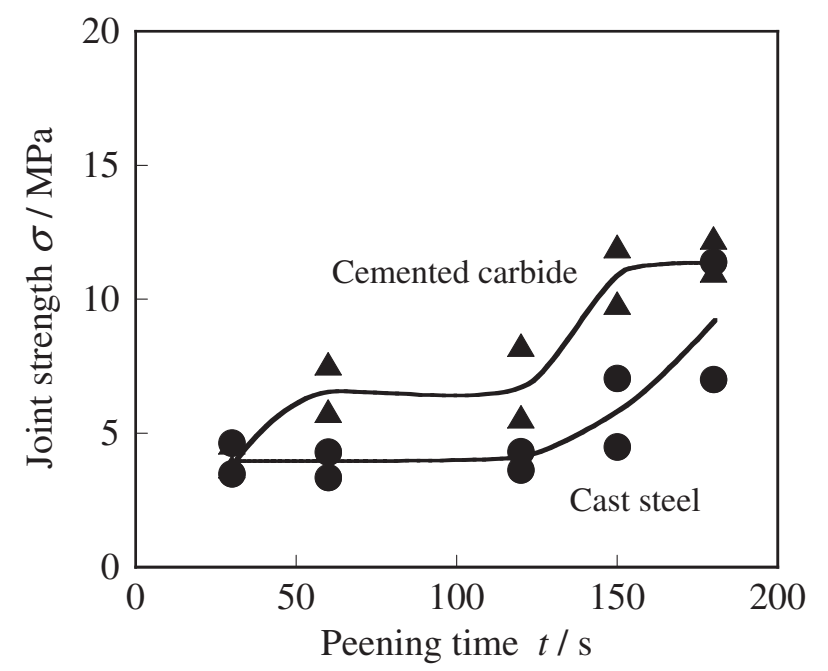

Fig. 6 Variation of joint strength with peening time for AZ31B/A1050 workpiece.

of joined workpieces with normal edges were added for comparative purposes. The maximum tensile load, measured by a tensile test, was consequently higher. The joint strength of the modified workpieces was more than twice that of the unmodified workpieces, and changing the edge shape also improved joinability.

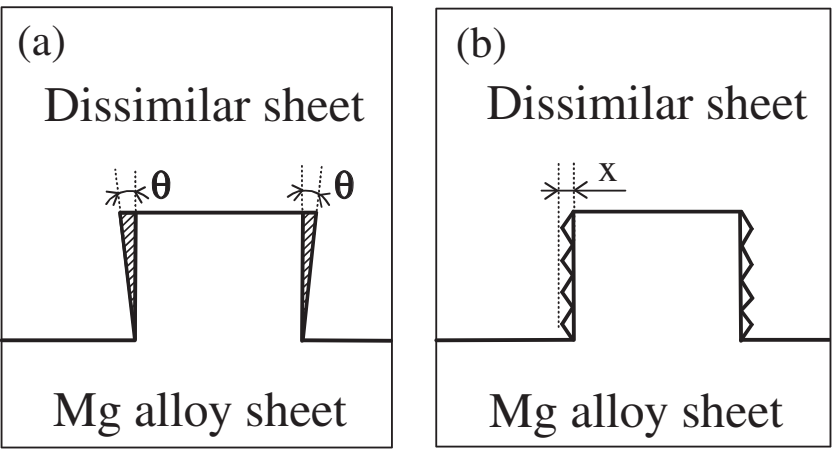

Fig. 7 Schematic illustrations of the modified shapes of the convex part. (a) Trapezoidal type, (b) Jagged type.

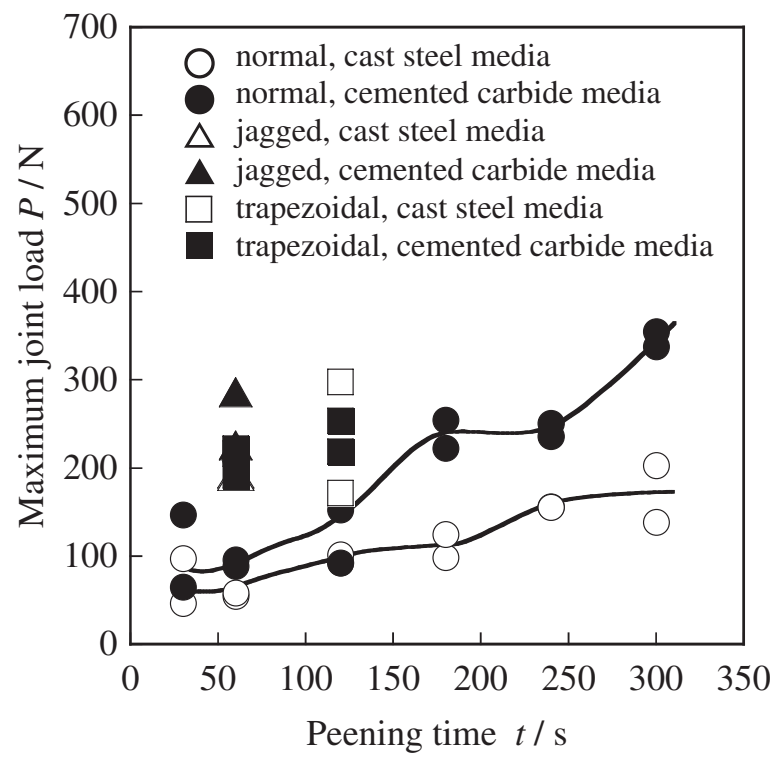

Fig. 8 Variation of the maximum tensile load and peening time for joined AZ31B/SPCC workpieces with the modified shape of contact edge.

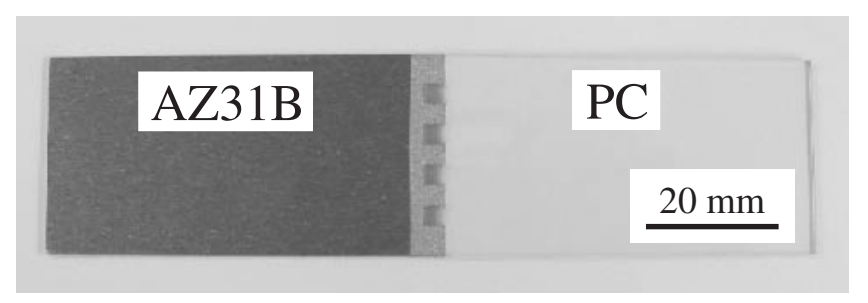

Fig. 9 Appearance of butt joined AZ31B/PC workpiece after shot peening.

\subsection{Joining with nonmetal sheet}

The butt joining of the magnesium alloy sheet with nonmetal sheets was tried to examine whether butt joining is possible. The appearance of the butt joined workpieces for AZ31B/polycarbonate (PC) is shown in Fig. 9 at a peening time of $30 \mathrm{~s}$. The AZ31B sheet was successfully joined with the PC. However, the joint strength of the AZ31B/PC workpiece is lower than that of the AZ31B/metal workpiece (see Fig. 4). The mean value was about $4 \mathrm{MPa}$ when the peening time was $30 \mathrm{~s}$. 


\section{Conclusions}

The shot peening process is characterized by large plastic deformations near the surface of the material. In the present study, butt joining between the magnesium alloy sheet and the dissimilar metal sheets was performed by means of shot peening. Tensile strength was measured to examine the influences of peening time and shot media on joinability. The magnesium alloy sheet and the dissimilar metal sheets were successfully joined by shot peening. The use of cemented carbide media and changing the edge shape were both very efficient in improving joinability. However, the joint strength is lower than the flow stress of base material. Although further investigations are needed to improve the joinability, we found that the present method can be used for butt joining of magnesium alloy sheet with dissimilar material sheets without melting.

\section{Acknowledgments}

The authors would like to thank Prof. K. Fukaura for valuable discussions. This research was supported in part by a grant from the Amada foundation for metal work technology.

\section{REFERENCES}

1) D. Q. Sun, D. X. Sun, S. Q. Yin and J. B. Li: ISIJ Int. 46 (2006) 12001204.

2) P. Liu, Y. Li, H. Geng and J. Wang: Mater. Lett. 61 (2007) 1288-1291.

3) M. Fujie, K. Nakata and M. Ushio: Trans. JWRI 32 (2003) 39-40.

4) G. Song, L. Liu and P. Wang: Mater. Sci. Eng. A 429 (2006) 312-319.

5) A. Munitz, C. Cotler and H. Shaham: J. Weld 79 (2000) 202-208.

6) X. Wang and K. Wang: Mater. Sci. Eng. A 431 (2006) 114-117.

7) H. Zhang, H. Wu, J. Huang, S. Lin and L. Wu: Rare Metals 26 (2007) $158-162$.

8) Y. Kataoka: J. Surface Finishing Soc. of Japan. 52 (2001) 191-194.

9) T. H. Van Steenkiste, J. R. Smith and R. E. Teets: Surface and Coatings Technology 154 (2002) 237-252.

10) Y. Harada, K. Mori and S. Maki: J. Mater. Proc. Technol. 80-81 (1998) 309-314.

11) Y. Harada and N. Matsuo: Key Eng. Mater. 274-276 (2004) 433-438.

12) Y. Harada, K. Mori and S. Maki: J. Mater. Proc. Technol. 125-126 (2002) 525-531.

13) Y. Harada, N. Tsuchida and K. Fukaura: J. Mater. Proc. Technol. 177 (2006) 356-359.

14) Y. Harada and K. Fukaura: Key Eng. Mater. 340 (2007) 865-870. 